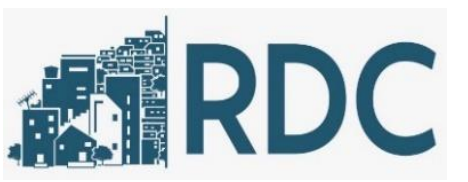

\title{
TURISMO LOCAL E O CONVIVER EM OURO PRETO EM TEMPOS DE PANDEMIA: LUGAR DE ENCONTRO E DE DESENCONTRO DOS MORADORES
}

Local Tourism And Coexisting In Ouro Preto In Pandemic Times: Place Of Meeting And Failure In Meeting Of The Residents

\section{Kerley Santos Alves}

Universidade Federal de Ouro Preto - UFOP, Ouro Preto, MG, Brasil

Lattes: http://lattes.cnpq.br/0155112780470566 Orcid: http://orcid.org/0000-0001-6215-3457

E-mail: kerleysantos@yahoo.com.br

\section{Welington Ribeiro Aquino Marques}

Pontifícia Universidade Católica de Minas Gerais - PUC-Minas, Belo Horizonte, MG, Brasil Lattes:http://lattes.cnpq.br/4089791705266536 Orcid: http://orcid.org/0000-0001-5514-6689

E-mail: welingtonribeirom@hotmail.com

\section{Eberte Moura Bretas}

Universidade Federal de Ouro Preto - UFOP, Ouro Preto, MG, Brasil

Orcid: http://orcid.org/0000-0001-7215-9983

E-mail: eberte1@yahoo.com.br

Trabalho enviado em 01 de outubro de 2020 e aceito em 04 de janeiro de 2022

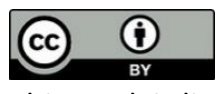

This work is licensed under a Creative Commons Attribution 4.0 International License. 


\section{RESUMO}

Este trabalho tem como objetivo compreender, a partir das lógicas territoriais da cidade e das atividades da extensão universitária do Projeto Conviver, mesmo em tempos de pandemia, como as suas ações podem representar possibilidades de desenvolver o sentimento de pertencimento e a inclusão do morador no contexto do turismo local na cidade de Ouro Preto em Minas Gerais. O projeto propõe inserir, na atividade turística e cultural, pessoas em situação de vulnerabilidade social dos Centros de Referências em Assistência Social (CRAS) e Abrigos Institucionais de Ouro Preto, capacitando-os para geração de renda e incentivo a apropriação da cidade por meio da interdisciplinaridade entre planejamento turístico, psicologia socioambiental, direitos humanos e participação popular. Os procedimentos metodológicos adotados foram: revisão bibliográfica, realização de entrevistas em profundidade e observação participante nas atividades presenciais e remotas do projeto. Pode-se considerar que a cidade vem ao longo do tempo sofrendo modificações socioespaciais, ao usarem os espaços da cidade, ao darem significado e sentido a determinados lugares, esses moradores constroem e demarcam territórios por onde circulam. Antes mesmo do advento da pandemia, a centralidade das atividades, cada vez mais apontava para um aumento no grau de isolamento físico e simbólico dos moradores na cena turística, e consequentemente, da sensação de não fazer parte dele. No contexto da pandemia, as novas tecnologias possibilitaram a recriação de experiências na cidade e estímulo a novas formas de sociabilidades, proporcionando a troca de experiências entre os participantes em um espaço urbano híbrido de convívio.

Palavras-chave: Turismo. Apropriação urbana. Território. Pandemia. Ouro Preto.

\section{ABSTRACT}

This communication aims to understand, from the territorial logic of the city and the activities of the Conviver project, even in times of pandemic, how their actions can represent possibilities to develop the feeling of belonging and the inclusion of the resident in the context of local tourism. It was built from bibliographic review and participant observation in the face-to-face and remote activities of the project. It can be considered that the city has been undergoing socio-spatial changes over time, when using city spaces, when giving meaning and sense to certain places, these residents build and demarcate territories where they circulate. Even before the advent of the pandemic, the centrality of activities, increasingly pointed to an increase in the degree of physical and symbolic isolation of 
residents in the tourist scene, and consequently, the feeling of not being part of it. In the context of the pandemic, new technologies made it possible to recreate experiences in the city and stimulate new forms of sociability, providing the exchange of experiences between participants in a hybrid urban space of conviviality.

Keywords: Tourism. Urban appropriation. Territory. Pandemic. Ouro Preto.

\section{INTRODUÇÃO}

A atividade turística, por excelência, é urbanizadora, e cada vez mais, é evidente a ocupação territorial desordenada, a construção de equipamentos a fim aumentar o potencial competitivo das localidades o que contribui para alterar a imagem das cidades, principalmente naquelas possuidoras de atrativos histórico culturais expressivos e acabam por interferir de forma perene na relação homem-espaço. O uso que se faz do espaço, determina uma produção socioespacial caracterizada pela presença de formas estabelecidas pelas relações capitalistas contemporâneas.

Nesses termos, a produção turística e o uso do espaço ocorrem de modo desigual e contraditório, refletindo as relações sociais diferenciadas de poder, configurando um território daqueles que controlam o espaço, enquanto outros são controlados por meio dele. Ademais, em tempos de pandemia ${ }^{1}$, hoje, a cidade e suas relações são produzidas em parte, de modo real e concreto, concomitantemente em outra parte, de modo virtual e possível. Logo, constitui-se enquanto global, apresentando tendência à homogeneização, ao mesmo tempo que permite a diferenciação.

Assim, as possibilidades de convívio estão articuladas ao plano territorial revelado como modo de vida, construção cultural, hábitos, valores, usos e, simultaneamente, no plano do lugar que se refere ao processo de constituição do sujeito, das vivências revelando-as em suas múltiplas dimensões. No contexto das cidades turísticas, as histórias dos moradores são aquelas que foram produzidas e produzem o espaço que a ele se imbrica. Desse modo, elas podem ser apropriadas. Mas são também histórias paradoxais de exclusão e inclusão, de resistências e existência, constituídas por pequenas

\footnotetext{
${ }^{1}$ Doença causada pelo coronavírus SARS-CoV-2, que apresenta um quadro clínico que varia de infecções assintomáticas a quadros respiratórios graves. A maioria dos pacientes com COVID-19 (cerca de 80\%) podem ser assintomáticos e cerca de $20 \%$ dos casos podem requerer atendimento hospitalar por apresentarem dificuldade respiratória e desses casos aproximadamente $5 \%$ podem necessitar de suporte para o tratamento de insuficiência respiratória (suporte ventilatório). Organização Mundial de Saúde. (OMS, 2020).
} 
formas de apropriação. No amplo espaço em que se descortina o patrimônio mundial da humanidade, a cidade de Ouro Preto ${ }^{2}$ guarda um acervo histórico-cultural que se expressa, sobretudo, em seu rico patrimônio arquitetônico e nas histórias da sua gente. Nisso, o que se pode observar?

Ouro Preto conserva a arquitetura colonial, com casas centenárias, igrejas símbolo da arte barroca e museus que carregam histórias da cidade. Essas, por sua vez, se confundem com a própria história do Brasil. O efeito disto, é a intensa atividade turística na cidade, que recebe visitantes de várias partes do mundo durante o ano todo. No entanto, é de se surpreender que pessoas atravessem o mundo para conhecer a igreja de São Francisco, o museu da Inconfidência, a Casa Gonzaga, a praça Tiradentes, a Universidade Federal de Ouro Preto (UFOP), entre outros espaços atrativos da cidade, enquanto os próprios moradores não os conhecem e não sabem das suas histórias e particularidades, ainda mais quando os residentes da cidade têm entrada franca nos edifícios históricos. Podemos inferir que isto acontece porque os ouro-pretanos, em sua maioria, não se sentem convidados a frequentar esses lugares, não são incluídos na cena turística e cultural da cidade ou até mesmo porque, ainda, não foi despertado o interesse pela história da sua cidade natal. Ao se tratar do morador da cidade turística e a apropriação do território, compreende-se diversos aspectos, tais como: políticas públicas, educação, relações culturais, entre outros, que podem ocasionar tanto a proximidade, no sentimento de pertencer, quanto o afastamento, no sentimento de não pertencer à cidade.

Fica subentendido que o centro histórico de Ouro Preto é local para turistas, dito que é uma área supervalorizada do setor imobiliário e comercial, com lojas e espaços "gourmetizados", dos quais a população local, por vezes, que apresenta vulnerabilidade econômica, não tem condições de frequentar e consumir. Como consequência, temos implicações no âmbito social porque os moradores não sentem que pertencem a essa realidade e deixam de vivenciar as experiências culturais que a cidade oferece.

Nesse sentido, o projeto de extensão intitulado “Conviver: valorização e capacitação de pessoas para o turismo vivo" vinculado a Pró- Reitoria de Extensão Universitária (PROEX/UFOP), surge no ano 2017 e permanece até o ano de 2019 com a efetivação de ações presenciais e a partir de 2020 devido a pandemia de COVID 19, dá continuidade com ações remotas, semanalmente. Tem buscado por meio de ações inclusivas, estimular seus participantes a se apropriarem da cidade e da atividade turística, com vistas ao conhecimento e apropriação de si como sujeitos e não assujeitados à cidade,

\footnotetext{
${ }^{2}$ No ano de 1980 é considerada Patrimônio Cultural da Humanidade pela Organização das Nações Unidas para Educação, Ciências e Cultura. A cidade se tornou a primeira no país a receber tal título. (UNESCO, 1980).
} 
quiçá, a consequência da geração de renda por meio da economia solidária. Para proporcionar a interação e a transformação da realidade social, por meio da extensão universitária, abrange atividades culturais, sociais e econômicas, sem desconsiderar os valores das comunidades participantes. Essa abordagem deve propor uma escuta ética e, além disso, um entendimento para um turismo como atividade, aqui, conceituado como turismo vivo.

De acordo com Alves (2019, p.35), turismo vivo é aquele que é, em princípio, teleologia, liberdade, criatividade e tem em consideração a realidade social e cultural de cada comunidade e sujeitos envolvidos na atividade (turistas, moradores, trabalhadores).

Destarte, as ações desenvolvidas no projeto Conviver deixam de ter caráter assistencialista e se transformam em socioeducativas ao adotar estratégias para favorecer a inserção e permanência no mercado de trabalho as quais requerem, sobretudo, a valorização das pessoas.

$\mathrm{O}$ artigo tem como objetivo geral compreender, a partir das lógicas territoriais e das atividades do Projeto Conviver, mesmo em tempos de pandemia, como suas ações têm buscado o direito a cidade turística por seus moradores. Foi construído desde a revisão bibliográfica, observação participante e realização de entrevistas realizadas mediante adesão dos participantes. Posteriormente, foi realizada a análise qualitativa dos relatos, percepções e trabalhos desenvolvidos pelo grupo de participantes. A proposta foi submetida e aprovada no Comitê de ética em pesquisa e o modelo de Termo de consentimento livre esclarecido foi utilizado. Tendo como base a pesquisa bibliográfica, este artigo apresenta um referencial teórico preliminar, com algumas considerações sobre as relações entre a produção de espaços urbanos advindas da inserção do turismo a fim de estabelecer discussões sobre a cidade Ouro Preto na perspectiva de espaço urbano fragmentado. Bem como, das possibilidades de desenvolver o sentimento de pertencimento e a inclusão do morador no contexto do turismo local em tempos de pandemia e uso das tecnologias.

\section{A RELAÇÃO HOMEM-ESPAÇO NAS LÓGICAS DA PRODUÇÃO DO ESPAÇO}

A "evolução da sociedade" foi possível por causa da interação do homem com o espaço diferenciando-o de outros seres vivos, essa interação vai acontecer a medida em que o ser humano modifica o seu entorno para garantir sua sobrevivência. Com o passar dos anos, foram se modificando as relações entre o homem e a natureza, tendo como recorte para este estudo, o advento da Revolução Industrial. Essa época marca o nascimento do capitalismo industrial que vai trazer consigo desenvolvimento tecnológico e transformação das cidades na díade industrialização e urbanização. 0 
espaço urbano (cidade) sofre transformação de uso com o surgimento do capitalismo, passando de lugar de dispersão e concentrador de fluxo para lugar de obtenção de lucro. Essa relação passa a ser uma relação de valor-espaço onde o homem agrega formas humanizadas ao espaço e se apropria de recursos naturais para adquirir lucro, tendo como uma das consequências a segregação sócio espacial.

De acordo com Moraes e Costa (1999, p.123), a relação sociedade-espaço é, desde logo, uma relação valor-espaço, pois substantivada pelo trabalho humano. Por isso, a apropriação dos recursos próprios do espaço, a construção de formas humanizadas sobre o espaço, a perenização (conservação) desses construtos, as modificações, quer do substrato natural, quer das obras humanas, tudo isso representa criação de valor.

Para Correa (2004, p.12) o espaço de uma grande cidade capitalista constitui-se, em um primeiro momento, de sua apreensão no conjunto de diferentes usos da terra justapostos entre si. Tais usos definem áreas, como o centro da cidade, local de concentração de atividades comerciais, serviços e gestão, áreas industriais, áreas residenciais distintas em termos de forma e conteúdo social, de lazer, e, entre outras, aquelas de reserva para futura expansão. A "urbanização é um processo e a cidade uma forma espacial, que se pode compreender e verificar o produto e o produtor de uma determinada realidade", daí a necessidade de um planejamento a fim de minimizar as contradições do espaço construído, as cidades, proporcionando melhor qualidade de vida para seus habitantes. (COSTA, 2008, p. 92).Desse modo, estudar o espaço pelo viés econômico é superficial, pois as relações entre homem-espaço extrapolam o aspecto da produção, tendo em vista que o espaço é fator determinante para as relações humanas. $O$ espaço urbano das sociedades capitalistas é formado por conjunto de terras que tem o seu papel e valor de uso específico, tendo como característica a fragmentação e a articulação entre suas regiões formando redes interligadas e atendendo aos aspectos sociais, culturais, políticos e econômicos. No sistema urbano em análise, o processo de turistificação ocorre mediante conflitos entre o valor de uso e o valor de troca, entre a mobilização da riqueza (em dinheiro e em papel) e o investimento improdutivo na cidade, entre a acumulação do capital e sua dilapidação nas festas, entre a extensão do território dominado e as exigências de uma organização severa desse território em torno da cidade dominadora, autóctone versus estrangeiro. Esta última se protege contra qualquer eventualidade através da organização coorporativa que paralisa as iniciativas do capitalismo bancário e comercial. (LEFEBVRE, 2001, p14).

As relações sociais em Ouro Preto podem ser entendidas como causadoras de impactos positivos e negativos em que o turismo pode ser o indutor de desenvolvimento econômico mas também pode ser responsável pelo aumento da disparidade social na região, resultando na criação 
de um espaço urbano dialético (pobreza e prosperidade, desenvolvimento econômico e vida social). Os elementos complicadores se extrapolam, tendo a atividade turística como fenômeno complexo, capaz de abarcar aspectos econômicos, sociais, políticos, culturais, refletindo expressões territoriais e espaciais diversas. Desse modo, as contradições que emanam do desenvolvimento do turismo expressam-se no espaço urbano, o qual não será homogêneo com relação à implantação e ao uso e produção do espaço. Tal heterogeneidade é caracterizadora do fenômeno da segregação espacial, refletida nas formas de "valorização do solo, da oposição entre capital e trabalho no espaço urbano: desigualdade entre o centro e a periferia; oportunidades de lazer, tendência à formação de áreas especializadas dentro da cidade (zonas industriais, comerciais, residenciais, etc.)". (BARCELLOS, 1986, p.7).

O processo de urbanização em Ouro Preto tem relação direta com o desenvolvimento do turismo, cria uma nova racionalidade no uso e na ocupação do território. Problemas, como a ocupação de áreas irregulares, onde não há uma preocupação com o uso e ocupação do solo, ou seja, áreas com fragilidade ambiental são ocupadas, sem que haja uma política urbana eficaz, onde o seu papel seria reestruturar e não manter os mecanismos que possibilitem a especulação. "A especulação imobiliária leva os residentes para a periferia que, sem infraestrutura básica que dê condições de moradia, faz com que se tornem bairros periféricos, desarticulados do contexto urbano." (SILVA JUNIOR, 2008, p. $6)$.

No que tange as relações de apropriação e/ou (des) apropriação do território turístico, estão vinculadas à variados agentes, propiciando uma reprodução do sistema social. Gomes (2002) enfatiza que a apropriação do espaço está relacionada a ocupação de um determinado lugar, como por exemplo as ruas, sendo o simbólico, parte das experiências e modos de pertencer ao território.

No campo do simbólico, o sentimento de pertencimento está relacionado à aproximação, bem como, da ligação com o local. Pertencimento, ainda pode significar, "fazer parte de um grupo ou lugar que pode ser a cidade, a vizinhança, a uma instituição social". (CHEUNG et al, 2017, p. 227). Para além disso, o território não é representado apenas pelas suas delimitações geográficas, mas, pelas relações existentes entre as populações que ali transitam, possuem valores, longa duração constroem afetos e sua identidade. De tal modo que a conotação geográfica da identidade abrange também as "ligações de pertença que criam território" (CALDO, 1996, p. 285). Se entendido como espaço de pertença, torna-se assim um produto afetivo, o que possibilita fazer referência ao "espaço vivido". Conforme assevera Santos (2000), o território é mais do que a superposição de um conjunto de sistemas naturais de coisas criadas pelo homem. Pollak (1992) contribui significativamente ao retratar 
a relação entre identidade e memória, na qual se destacam as fronteiras de pertencimento e o sentimento de coerência, indicando três elementos constitutivos da identidade: os acontecimentos, as pessoas e personagens e os "lugares" da memória.

Destarte, o território é "o chão e mais a população, isto é, uma identidade, o fato e o sentimento de pertencer àquilo que nos pertence. $O$ território é a base do trabalho, da resistência, das trocas materiais e espirituais e da vida sobre as quais ele influi". (SANTOS, 2000, p. 96).

Assim, a relação identidade e pertencimento, extrapola a identificação do morador com o seu lugar de nascimento, abrange formas variadas de vivenciar e se apropriar da cidade.

Na perspectiva da cidade turistificada ela pode ser "alvo da interferência de políticas públicas e privadas, apresentando atividades hegemonicamente priorizadas aos turistas e não aos residentes" (CORIOLANO e SILVA, 2005, p, 119), assim, nela, há o direcionamento das atividades para o atendimento dos que vem de fora, alterando a configuração em função de interesses mercadológicos, sinalizando para a dinâmica de inclusão e exclusão de comunidades locais.

Nesses termos, a possibilidade de inclusão no processo de turistificação decorre das condições históricas estruturais reais no território assim como, o sentimento de pertença pode ser influenciado por diferentes fatores. Há de se considerar, ainda, que o advento da tecnologia possibilita novas formas de socialização. Milton Santos (2000) afirma que, há uma crença de que a difusão instantânea das notícias realmente informa as pessoas, partindo do pressuposto do encurtamento das distâncias, dando uma impressão de homogeneização, quando na verdade as diferenças locais são aprofundadas. Partindo dessa assertiva entende-se que a exclusão da população local é mais lucrativa do ponto de vista dos interesses dominantes. Os moradores, por vezes, ficam fora do processo, ou seja, nas "áreas descobertas pelo turismo" não são, assim, consideradas agentes da transformação de suas localidades em destinos turísticos de prestígio nacional e/ou internacional, tendo em vista suas desvantagens econômicas e despreparo para a atividade.

O turismo possui evidências negativas que acompanham a história, como por exemplo a xenofobia, nesse sentido, a sociabilidade é permeada pela lógica mercantil, pelo distanciamento da população local dos atrativos e pelo estranhamento entre moradores e visitantes. Esse estranhamento também pode ser entendido como turismofobia. A população local é afetada pelos visitantes, remete ao chamado "overtourism", descrito por Goodwin (2019), situação em que o excesso de visitantes traz para turistas a sensação de que a qualidade da experiência se deteriorou e para os moradores, a especulação do mercado imobiliário, o aumento do custo de vida, o incômodo inerente a lotação dos espaços turistificados, o barulho, a geração do lixo, sobrecarga das 
infraestruturas. Essas são situações que permitem questionar o discurso da generalização do turismo como algo totalmente benéfico. Está evidenciado que ele pode representar um "novo meio urbano que reforça e valoriza desigualdades e separações, e é, portanto, um espaço público não democrático e não moderno" (CALDEIRA 2000, p.12). Cabe ressaltar que a cidade turistificada não se constitui apenas, pela funcionalidade ou pela estrutura, mas também, pelas interações possíveis, nos espaços de circulação, na convivência, na socialização, no aprendizado, construindo vivências, socializações e inserção produtiva.

Para tanto, foi escolhida a cidade de Ouro Preto e o projeto Conviver, a fim de perceber como a produção espacial realiza-se no plano do cotidiano e aparece nas formas de apropriação, utilização dos atrativos turísticos e culturais da cidade. Uma vez que cada sujeito se situa num espaço, o lugar permite pensar o morar, o trabalho e o lazer enquanto situações vividas, revelando, no nível do cotidiano, paradoxos e hierarquias inerentes ao direito à cidade, o que será discutido a seguir.

\section{OURO PRETO SOBRE O ENFOQUE DO DIREITO A CIDADE TURÍSTICA POR SEUS MORADORES ANTES E PÓS PANDEMIA}

A relevância das ações extensionistas efetivadas no Projeto CONVIVER: valorização e capacitação de pessoas para o turismo vivo, é potencializada ao compreendermos a trajetória e o alcance as dimensões informativa e formativa do mesmo, com vistas à mobilização social. Em conjunto, membros da UFOP e profissionais da Secretaria Municipal de Desenvolvimento Social, Habitação e Cidadania trabalham em dois módulos, sejam eles: Módulo integrador e Módulo específico.

O Projeto tem como público alvo pessoas de todas as idades, que de algum modo estejam vivendo em situação de vulnerabilidade social, indicadas pelos CRAS-Ouro Preto e Casa Lar. Para que houvesse alinhamento entre a Universidade, prefeitura e comunidade foi necessária uma sistematização entre a Secretaria Municipal de Desenvolvimento Social, Habitação e Cidadania, o Centro de Referência de Assistência Social e na segunda etapa do projeto tivemos o apoio da Secretaria Municipal, Turismo, Indústria e Comércio. Dentre as atribuições, destaca-se: Executar a política municipal do Desenvolvimento Social, de Assistência Social e Cidadania; Articular-se com entidades ligadas ao setor no Município; Desenvolver programas e projetos de cunho social que visem melhorias no tocante à habitação, à infância e adolescência, à geração de emprego e renda, aos portadores de necessidades especiais, aos idosos e à mulher; incentivar a prática da cidadania através de intensa 
articulação com ONGs, escolas, igrejas e outras organizações da sociedade civil, entre outras atividades.

É importante enfatizar que este estudo se pauta na compreensão do sentimento de pertencimento, apropriação e socialização de moradores, demonstrando a influência do território no cotidiano e nos anseios destes indivíduos, para tanto, foram priorizadas as categorias: local de permanência, apropriação do território, percepção do espaço turístico e lugares de convivência.

As atividades se iniciaram no ano de 2017 e são oferecidas semanalmente, alternando o espaço da universidade e pontos na cidade de Ouro Preto, bem como distritos e cidades vizinhas.

O público é composto majoritariamente por mulheres. Por vezes, estas incluem os próprios maridos e filhos que passam a participar. No início, nos anos de 2017 e 2018, a quase totalidade das participantes advinha de encaminhamentos dos Centros de Referência de Assistência Social - CRAS do município. Com o decorrer das atividades, sobretudo desde 2019 passou-se a contar também com convidados e convidadas de outras procedências, como amigos e familiares das primeiras participantes. Destaca-se que estas começaram a frequentar com assiduidade e interesse e a partir daí passaram a convidar outras pessoas por iniciativa própria e de forma espontânea. Eis aqui uma política pública que vai além dos limites inicialmente estabelecidos. Houve em vários casos uma passagem da posição de participante para também de agente e operador no Projeto. Devido a mostras e provas das participantes de insuspeitada habilidade e conhecimento para lidar com temas pertinentes aos encontros, várias delas foram convidadas a comporem a equipe de coordenação. Passaram a trabalhar com o corpo acadêmico: professor titular, bolsistas, alunos voluntários, além de colaborador externo. Desde então prestam uma contribuição imprescindível, com os seus saberes a altura dos demais a todo o tempo.

No Projeto Conviver se preza pelo planejamento das atividades, bem como por uma ótima proximidade às referências metodológicas. Assim se trabalha alinhadamente às próprias diretrizes que são genuínas ao projeto. A metodologia está como consequência e efeito de um princípio norteador. Assim se trabalha alinhadamente às próprias diretrizes que são genuínas ao Projeto ou seja, não se trabalha de forma inadvertida quanto ao fato de que práticas coletivas não são fáceis de se conduzir. O fazer junto, fazer com o outro é algo que requer trabalho e muita paciência, pois o que é obtido são efeitos não acabados no lugar de resultados enquadrados. Viver junto não é fácil nem imediato.

A equipe sabe que só se obtém efeitos de crescimento junto às participantes se estes se derem primeiro junto aos membros da coordenação. Para se tratar de inclusão é primeiro preciso estar incluído! 
Nas reuniões de planejamento há discussões sobre os encontros, sobre cada participante individualmente, prática de leituras e trocas de referências bibliográficas. Além de produção de reflexões. As ações surgem como inflexões advindas de forma coletiva e não como meras prescrições. Um ambiente fértil em trocas e de emergência do novo.

Assim, temos que à cada membro da equipe é possível acolher as participantes com singular propriedade.

Para que se passe do planejamento à ação entendemos que um outro nome que se pode dar para o termo inclusão é a produção de novos lugares simbólicos. Assim, segue um breve exemplo da prática.

A equipe se reuniu para decidir sobre uma atividade. A discussão se voltava para o princípio de que as participantes poderiam galgar um lugar doravante reservado quase que exclusivamente aos turistas. Alguém se lembrou de um passeio de trem entre as cidades de Ouro Preto e Mariana. Uma provocação assim enunciada:

“- Quem disse que o passeio de trem é só para os turistas que vêm de fora?"

A atividade estava, portanto, definida de forma participativa e como um efeito de uma reflexão. A vizinhança topológica das moradoras da cidade com a estação de trem e seu projeto de lazer não bastavam para que elas usufruíssem do passeio. Foi necessária a ação dos agentes do projeto para servir de ponte entre o sistema e o povo. Então, foi realizado o convite para a atividade, que, por sua vez, foi prontamente aceito e recebido com muito bom grado e entusiasmo.

Importa aqui uma sutileza que fora observada. Na viagem de ida as crianças foram juntas de suas mães e avós, aconchegadas no colo ou dividindo a poltrona. Já na viagem de volta, em meio à tranquilidade e diversão, houve uma mudança importante para um observador interessado na inclusão. É que as crianças fizeram a viagem de volta separadas dos adultos. Na entrada do vagão, elas se sentiram à vontade para ocuparem um lugar próprio. Desejaram dispensar, por um momento, a proteção materna integral. Isso em troca de um lugar que fazia outro sentido para elas, já que compartilhado entre a própria geração. A inclusão aqui se deu de forma genuína e original porque as crianças formaram seu grupo por própria iniciativa. Não houve um planejamento recreativo por parte de nenhum adulto. Supervisionadas com uma boa distância, as crianças inventaram para si um lugar de trocas seguras em seu próprio, e, porque não dizer, pequeno território. Para fortalecer as ligas de nossa observação, temos:

A convivência é a contingência do encontro que acontece, independentemente de planos, e deve ser levada em conta no que concerne à proteção possível: 
'Solidariedade é um jogo absolutamente sem projeto nem plano. Sem projeto na medida em que não se baseia em identificações aos mais velhos [...] Sem plano na medida em que os jovens podem ir mais longe do que a orientação $p s i$ [e pedagógica] prévia. (BRISSET, MILLER, 2013, p. 58).

Nesse sentido, a convivência deve ser uma via de não dupla, traz consigo a ideia de proteção na perspectiva da solidariedade, da relação de convivência mútua dos indivíduos que dividem um espaço comum. Seja fora do espaço da Universidade ou dentro dela, participando efetivamente dos eventos e ações. Anualmente o projeto participa do Encontro de Saberes, um evento técnico-científico realizado pela UFOP para apresentar os projetos de extensão. Na última edição o Conviver foi representado por uma das bolsistas. De forma usual, apresenta-se as atividades do ano e a metodologia de forma expositiva, acrescidas de material audiovisual. Cabe citar aqui a boa impressão que foi causada no público, ilustrada por uma fala:

“- Gente! Eu estou morrendo de inveja desse projeto." (Risos).

Neste evento colhemos interessante observação de um pesquisador da área. Observou que no Conviver se faz turismo de base comunitária ao contrário, ou seja: em vez de receber os turistas, os moradores estavam, eles sim, participando de atividades turísticas em sua própria cidade. Mas na verdade podemos afirmar que o turismo de base comunitária é realizado concomitantemente, já que os moradores são convocados tanto como turistas, mas também como agentes do turismo local.

Despertar no participante a criatividade produtiva para gerar renda utilizando recursos das inúmeras atrações turísticas da cidade, só é viável a partir do momento que ele conhece o meio em que está inserido, suas origens e tem orgulho disto. Denomina-se sentimento de pertencimento, cujo foi identificado como incomum entre os ouro-pretanos participantes do projeto. Segundo Silva (2018) a identidade e o sentimento de pertença de um lugar significam procurar compreender o entrelaçar das falas e conceitos que dão forma aos espaços. Os significados, os sentidos e os valores atribuídos a um espaço, e que constituem sua identidade e pertencimento são elaborados e reelaborados a cada momento. Considerando que a maioria dos participantes nunca havia visitado os principais atrativos turísticos de Ouro Preto, marcos da arquitetura barroca, mundialmente reconhecidos, foram propostas atividades com o objetivo de inserção na vertente turística da cidade as quais implicaram em experiências marcantes para todos os envolvidos observadas em depoimentos de alguns deles.

"É minha primeira vez no museu, foi uma bela experiência conhecer esse lugar incrível!" (Yhasmin Yonara, 20 anos, residente do distrito Santa Rita).

"É a primeira vez que participo do projeto Conviver, e sobre a visita guiada, gostei bastante, apesar de já ter vindo, e indico para todos que venham conhecer o museu de mineralogia." (Bruno Milagres, 18 anos, residente do distrito Santa Rita). 
"A visita foi maravilhosa, nunca tinha vindo. A biblioteca de obras raras é muito interessante." (Nelma Rodrigues de Oliveira, 61 anos, residente do bairro Novo Horizonte).

"Foi minha primeira vez no museu. Amei, foi muito interessante, vi muitas pedras que eu não conhecia, foi muita novidade para mim." (Andréa Brígida Campus Pinheiro, 35 anos, residente do distrito de Santa Rita).

"A visita ao museu foi muito interessante, eu já tinha vindo só para conhecer o espaço, mas nunca com uma visita guiada explicando a história, hoje foi mais interessante." (Gláucia Santa Cruz, 37 anos, residente da Vila São José).

"É minha primeira vez no museu de mineralogia, gostei muito dessa experiência nova, achei muito importante conhecer. E foi muito interessante conhecer as pedras do acervo." (Andréia Souza Alvarenga, 20 anos, residente do distrito de Santa Rita de Ouro Preto).

Os fragmentos evidenciam o prazer da descoberta, de uma nova experiência na cidade. 0 sentimento de pertencimento está ligado com a construção da identidade coletiva e individual que adquirimos ao longo da vida, através de fatos que venham a ficar marcados na memória. Zaoual (2006) discorre sobre economias locais ligadas ao Turismo, sendo assim, ele propôs o que chamou de teoria dos sítios simbólicos de pertencimento na formação e afirmação da identidade e na valorização do contexto social naquela localidade.

No ano de 2020, diante da situação de isolamento físico devido a epidemia, surge a proposta de dar continuidade às ações e promover o convívio e o senso de comunidade nas redes sociais, antes utilizadas de modo complementar às ações presenciais. O que exigiu o desenvolvimento de novas competências e habilidades da equipe (coordenadores, colaboradores externos a Universidade, bolsista e voluntárias) bem como, a manutenção dessas de modo efetivo.

Para tanto, nesse momento, a equipe foi consultada e, em votação unânime, aprovou a continuidade das atividades por meio da promoção de debates virtuais; socialização de temáticas virtualmente e promoção de minicursos, foram realizadas atividades integrativas, expositivas e conversas, dando enfoque ao módulo integrador com o objetivo de oportunizar o compartilhamento de conteúdos e vivências que favoreceram a reflexão crítica, a autopercepção, o resgate da autoestima, o espírito de cooperação, a troca de experiência, as manifestações culturais, o respeito às diferenças, entre outros conceitos.

Assim, foi possível englobar uma perspectiva multidisciplinar, por meio de uma metodologia lúdica e participativa, considerando as experiências de vida dos participantes, sua subjetividade, expressividade e criatividade. 
Deste modo, pressupõe que a partir desse novo olhar para o pertencimento e apropriação seja possível compreender as relações que se constroem também no ambiente virtual, enxergar o homem como ele realmente se apresenta. A este respeito, Zaoual $(2006$, p. 6) diz que: Como tentamos mostrar, um território, sendo um sítio, é povoado de sítios entrelaçados, únicos e assim por diante. Este processo se estende ao contínuo e desvenda a grande relatividade de nossas representações e de nossas práticas, assim como a impotência das ciências compartimentadas da ideologia acadêmica, empobrecida pelo reducionismo. Ter a oportunidade de adentrar e conhecer locais, o patrimônio, a história da cidade que, prioritariamente, são representados como "lugares para turistas".

Segundo Castrogiovanni (2001), a cidade é uma construção física e imaginária, compreende um lugar e faz parte do todo geográfico. O tecido urbano é dinâmico e está inserido no processo histórico de uma sociedade. "[...] A cada instante, há mais do que os olhos podem ver, do que o olfato pode sentir ou do que os ouvidos podem escutar. Cada momento é repleto de sentimentos e associações. A cidade é o que é visto, mas mais ainda, o que pode ser sentido." (CASTROGIOVANNI, 2001, p. 24).

A extensão universitária foi imprescindível para estimular os participantes na apropriação da cidade e, consequentemente, ao sentimento de pertença. Desde 2017, desenvolve atividades presenciais no campus da UFOP e em diferentes espaços da cidade e fora dela. Contudo, no ano de 2020, durante o tempo de distanciamento social devido a pandemia de COVID 19, as ações tem sido pautadas na metodologia remota. Destarte, o Conviver estendeu seus trabalhos nas redes sociais, a página no Facebook que já existia, passou a produzir conteúdos diversificados buscando expandir o trabalho já existente e, como aliados ao projeto, estendeu os trabalhos ao Instagram e Youtube, aumentando portanto o alcance do público e o feedback em relação ao apoio recebido e ao alcance que as redes sociais permitiram. No facebook, entre 02 a 09 de Junho de 2020 houve um alcance de 355 pessoas, engajamento (reações, comentários, compartilhamentos e cliques) teve um total de 193 ações. Atualmente no Instagram estamos com 820 seguidores, usando o serviço de informações do Instagram, no período de 02 a 09 de junho, o perfil alcançou 707 pessoas, 914 interações (ações realizadas na conta), e um de total de 2,845 impressões: que incluem visitas por hashtags, página inicial, visitas do perfil, 914 visitas ao perfil, e cerca de 221 likes. Majoritariamente 43\% do público possui a faixa etária de 35 a 44 anos, seguido por 30\% entre 18 a 24 anos e $15 \%$ entre 35 a 44 anos, $6 \%$ entre 45 a 54 anos. $68 \%$ do público é feminino, restando $32 \%$ homens. 
Cabe ressaltar que o projeto inclui moradores tanto da área central da cidade como da chamada periferia da cidade, abrangendo distritos. Assim, ele concorre contra uma mentalidade classista, qual seja, que reserva os ditos "melhores lugares" para os supostos mais abastados.

A abordagem compreende o modelo democrático, em que todos têm espaço de fala e voto. Mas principalmente vai para além deste modelo, dando relevo às falas singulares. Ou seja, se em determinado momento a equipe se vale do debate democrático para a condução dos casos, ela pode, em outros, se valer de outro recurso tão ou mais refinado, qual seja, a autoridade clínica (TEIXEIRA, 2010).

Tal iniciativa de extensão produz impactos na subjetividade dos sujeitos participantes. É notório na análise dos depoimentos as passagens de uma posição de queixa sobre a vida para uma produção ativa. A queixa passa a dar lugar para exposições de trabalhos os mais diversos, autorais e agradáveis ao público. De tal modo que há relatos de início de processos psíquicos patológicos, como depressão e alcoolismo, que foram interrompidos após períodos relativamente breves de adesão. Nesse sentido, foram delineadas metodologias participativas com base nas discussões nas redes sociais, com o enfoque na história regional como forma de construir um conhecimento histórico capaz de alicerçar o interesse pela história local, pela comunidade, pelos lugares de vivência dos participantes, por meio das percepções e experiências espaciais, compreendidas através da subjetividade e da cultura.

Sobre o projeto, eu achei muito interessante poder ter outros olhares, dentro da perspectiva de onde a gente passa todos os dias sem perceber detalhes que são muito importantes e descobrir histórias que a gente não tem nem noção que aconteceram. Pois, devido ao cotidiano e da correria, a gente não dá importância e valoriza essa cidade tão preciosa que a gente mora. Além disso, foi importante todo o convívio social e perceber que além de mim, outras pessoas não têm essa percepção sobre nossa cidade centenária" (Pedro, 35, São Cristovão).

Nunca imaginei que eu pudesse fazer viagens e visitas de modo virtual, quantas cidades e museus, tenho muita alegria de participar do projeto" ( Maria Helena, 57 anos, Cruzeiro Alto da Cruz)

Apesar de tudo, o projeto tem dado força para viver, para aprender a conviver, aprender tantas coisas da cidade que eu não sabia e participar de um modo diferente. ( Maria Amélia, 53 anos, Alto da Cruz )

Os fragmentos apresentados possibilitam a constatação de que os ouro-pretanos, participantes do projeto, não conhecem ou atrativos turísticos e culturais da cidade. Em contraponto, também, demonstram o discurso de pertencimento, sentimento em relação a cidade e ao Patrimônio. 
Nesse sentido, a sociabilidade é ressaltada nos encontros promovidos, semanalmente. É a forma de conviver diante das idiossincrasias porque é propriamente o modo pelo qual as pessoas experenciam os lugares, a mútua companhia, as formas de apropriação da cidade.

\section{CONSIDERAÇÕES FINAIS}

O turismo vem ganhando grande importância econômica no mundo moderno demandando intervenções espaciais para o seu desenvolvimento e para atender os pré-requisitos da sociedade capitalista. Enfatiza-se que a constituição social dos territórios se dá através das relações que os indivíduos e grupos humanos neles estabelecem. Essas relações no território abarcam conflitos, interesses, convergências e relações de poder.

Por vezes, a atividade turística está erroneamente associada apenas ao enfoque econômico. Antes mesmo de se planejar o turismo é coerente que os moradores, por meio de sensibilização e políticas locais, sejam incluídos para a participação efetiva neste meio. Em contrapartida, ao usarem os espaços da cidade, ao darem significado e sentido a determinados lugares, esses moradores constroem e demarcam territórios por onde circulam. Antes mesmo do advento da pandemia, a centralidade das atividades, cada vez mais apontava para um aumento no grau de isolamento físico e simbólico dos moradores na cena turística, e consequentemente, da sensação de não fazer parte dele.

A experiência com a pandemia de COVID-2019, até o momento, mostrou que a incerteza permanece alta e, portanto, a necessidade da atividade situada. Talvez uma lição que ainda estamos para chegar a um acordo nesta situação é que o tipo de turismo que coloca o lucro antes do princípio ético e, consequentemente, deteriora os valores globais para o desenvolvimento sustentável. Esse é o turismo tradicional que quando os planos de desenvolvimento pensam nas comunidades em segundo plano, residentes locais, são invisibilizados nas políticas públicas. Essa crise resultará em repensar o gerenciamento de destinos super saturados, melhorar a comunicação e uma implementação mais forte da comunicação online, novas formas de apropriação do território e sociabilidades.

No âmbito virtual, as atividades foram realizadas com a participação de equipe interdisciplinar de professores, colaboradores, bolsista e voluntários. Tendo em vista que as tecnologias da informação e comunicação (TICS) têm funcionado como facilitadoras das práticas extensionistas e essas configurarão uma nova cultura de integração e apropriação dos espaços , mais próxima e solidária da realidade; além de favorecer uma reflexão mais aprofundada sobre o papel da universidade e seu compromisso social. $\mathrm{O}$ uso das tecnologias para além de ser um meio de representação, possibilita a 
recriação de experiências na cidade e tornam-se uma ferramenta capaz de estimular sociabilidades , ajudando a unir pessoas e proporcionando a troca de experiências entre os participantes s em um espaço urbano híbrido de convívio. Acredita-se que a adesão se dá por ser interessante para cada participante e não por um frágil ideal institucional meramente quantitativo. Cada um e cada uma fica à vontade para participar, já que as vozes e os posicionamentos de cada participante do Conviver não são reivindicativos, nem demandantes. Assim, está assegurado um importantíssimo ganho: a presença da equipe para o grupo de participantes nunca é persecutória.

Desse modo, em meio a crise sanitária, todas as atividades estão em sistemas remotos, os encontros virtuais passam a representar novas formas de apropriação da cidade pelos moradores, em seus modos de ser e estar no mundo.

\section{Referências Bibliográficas:}

ALVES, K.S. Turismo e gestão social para o desenvolvimento local: interesses hegemônicos e contra hegemônicos. Relatório de Estágio pós doutoral. CES/Portugal, 2019.

BARCELLOS, Tanya M. de. Segregação urbana e mortalidade em Porto Alegre. Porto Alegre, FEE.BECKER, Bertha K: Levantamento e avaliação da política federal de turismo e seu impacto na região costeira. Brasília: Ministério do Meio Ambiente, dos Recursos Hídricos e da Amazônia Legal.1995.

BRISSET, F. O., MILLER A. L. S. Crianças falam! E têm o que dizer. Experiências do CIEN no Brasil Belo Horizonte: Scriptum, 2013.

CALDEIRA, T. Cidade de muros: crime, segregação e cidadania. São Paulo: Ed. 34 / EDUSP, 2000.

CALDO C., Geografia umana, Palermo, Palumbo, 1996

CASTROGIOVANNI, A. C.. Turismo e ordenação do espaço urbano. In: Castrogiovanni, Antonio Carlos(org) . Turismo Urbano. São Paul: Contexto, 2001.

CHEUNG, CK, CHEUNG, HY E HUE, MT. Educacional. Contribuições para os alunos pertencimento à sociedade, vizinhança, escola e família. Internacional . Diário de Adolescência e juventude, 2017.

CORRÊA, Roberto Lobato. O Espaço Urbano. São Paulo: Ática, 2004.

COSTA, R.A. Zoneamento Ambiental da Área de Expansão Urbana de Caldas Novas - GO: Procedimentos e Aplicações. 204 f. Tese (Doutorado em Geografia) - Programa de Pós-Graduação em Geografia - Universidade Federal de Uberlândia, Uberlândia, 2008. 
Cidades históricas brasileiras. Ouro Preto: História. Recuperado de:<Http://www.cidadeshistoricas.art.br/ouropreto/op_his_p.php>. Acesso em: 30/08/2020.

CORIOLANO, Luzia M, Neide Teixeira Silva e Silvio c. Bandeira de Melo .Turismo e Geografia: Abordagens Críticas. Fortaleza: UECE, 2005.

GOMES, Paulo Cesar da Costa. A condição urbana: ensaios de geopolítica da cidade. Rio de Janeiro: Bertrand Brasil, 2002.

GOODWIN, H. Crowding Out os locais: um modelo de gestão turística. In; Overtourism: Issues, realities and solutions (Vol. 1, pp. 125-138). De Gruyter Berlin / Boston, MA. 2019.

LEFEBVRE, Henri. Direito à cidade. Tradução Rubens Eduardo Frias. São Paulo: Centauro, 2001.

MORAES, Antônio C. R.; COSTA, Wanderley M. da. Geografia crítica a valorização do espaço. 2. ed. São Paulo: Hucitec, 1999.

POLLAK, M. Memória e identidade social. Estudos Históricos, Rio de Janeiro, v.5, n.10, 200-203.. 1992.

SANTOS, Milton. Por uma outra globalização: do pensamento único à consciência universal. São Paulo: Record, 2000.

SILVA, Amanda Maria Soares. Sentimento de Pertencimento e Identidade no Ambiente Escolar. Revista Brasileira de Educação em Geografia, Campinas, v. 8, n. 16, 2018.

SILVA JUNIOR, C.C. Especulação imobiliária e loteamentos irregulares: um estudo de caso em Caldas Novas-GO. Revista Mirante, Pirenópolis-Go, ISSN, 1981 4080, v.1, n.2, p. 1- 18, 2007.

TEIXEIRA, A. Metodologia em Ato, 2010, p. 34

ZAOUAL, H. Nova economia das iniciativas locais: uma introdução ao pensamento pós-global. Rio de Janeiro: DpeA- Consulado Geral da França:COPPE/UFRJ, 2006.

\footnotetext{
Sobre os autores:

Kerley Santos Alves

Pós-Doutora em Democracia, Cidadania e Direito pelo Centro de Estudos Sociais de Coimbra, Portugal. Doutora em Psicologia pela PUC-Minas com estágio Sandwich pela Universitat Autônoma de Barcelona - Espanha, Professora da Universidade Federal de Ouro Preto.

Universidade Federal de Ouro Preto - UFOP, Ouro Preto, MG, Brasil

Lattes: http://lattes.cnpq.br/0155112780470566 Orcid: http://orcid.org/0000-0001-6215-3457

E-mail: kerleysantos@yahoo.com.br

\section{Welington Ribeiro Aquino Marques}

Mestrando em Sustentabilidade socioeconômica Ambiental UFOP. Bacharelado e Licenciado em Geografia e meio ambiente Newton Paiva Pós-graduado em Engenharia Ambiental Feamig. Professor de Educação Profissional SEEMG.

Pontifícia Universidade Católica de Minas Gerais - PUC-Minas, Belo Horizonte, MG, Brasil

Lattes:http://lattes.cnpq.br/4089791705266536 Orcid: http://orcid.org/0000-0001-5514-6689

E-mail: welingtonribeirom@hotmail.com
} 


\section{Eberte Moura Bretas}

Especialista em Clínica Psicanalítica nas Instituições de Saúde pela Pontifícia Universidade Católica de Minas Gerais. Graduado em Psicologia Pela Universidade Federal de São João del Rei. Psicólogo na atenção básica de assistência social da prefeitura municipal de Ouro Preto-MG.

Universidade Federal de Ouro Preto - UFOP

Orcid: http://orcid.org/0000-0001-7215-9983

E-mail: eberte1@yahoo.com.br

Os autores contribuíram igualmente para a redação do artigo. 